\title{
Objective Evaluation and Factor Analysis of Bilingual Teaching in the Principles of Economics
}

\author{
Haiying Ma* \\ School of Economics, Northwest University for Nationalities Lanzhou (730124), P.R.China \\ Ixmahaiying8888@163.com
}

Keywords: Bilingual teaching; Principles of economics; Teaching effectiveness

\begin{abstract}
In this paper, we take the statistic sample of the students majoring in economics of 2013 grade of school of economics in Northwest University for Nationalities to evaluate the goal of bilingual teaching, and analyzes the factors that influence the effect of bilingual teaching. The author puts forward that we should improve the teaching effect of the principle of economics from the following three aspects: ensuring the orientation of teaching objectives, strengthening the construction of detailed teaching, and making appropriate teaching methods for students.
\end{abstract}

\section{Introduction}

With the further promotion of globalization, China is deeply involved in the global cooperation chain, it is more urgent for the talents with international vision and cross-cultural communication ability. At the same time, in the increasingly competitive employment market, the dual requirements of language and professional knowledge make the task of bilingual teaching more urgent. In 2001, The Ministry of Education in China on strengthening undergraduate education to improve the quality of teaching put forward the undergraduate education should create conditions for the use of English and other foreign language courses and professional courses. But in the area of high-tech biotechnology, information technology and other professional and to adapt to the financial, legal and other professional after China's accession to the WTO needs, but also to the first step, and strive to three years, foreign language teaching to reach 5\%-10\% courses. On the implementation of undergraduate teaching quality and teaching reform project (Higher Education 2007), the document pointed out to promote the bilingual education curriculum construction, explore teaching methods and effective mode, and effectively improve the English level of college students and the ability to use English in scientific research. These two documents have greatly promoted the bilingual teaching in China's colleges and universities.

Bilingual teaching is a complex concept. According to the British Longman Publishing House of the Longman applied linguistics dictionary explanation is the use of a second or foreign language in school for the teaching of contents subjects. That is the use of second language or foreign language teaching in various subjects. Baker believes that bilingual teaching is to use a simple label to summarize a complex phenomenon, including the following several different attributes: first, the type of learner; the target language used in the classroom. According to these different attributes, bilingual teaching mainly includes the following three main modes: transitional bilingual education, maintenance bilingual education and immersion bilingual education.

Bilingual teaching itself is a theory of the subject, but also a practical issue. this paper will focus on using statistical sampling data, qualitative research, the samples in the 2012 and 2013 grade majoring in economics of Northwest University For Nationalities to answer the following questions: what is the target of bilingual teaching for the principle of economics? What factors influence the effect of bilingual teaching? How to improve the quality of bilingual teaching? Based on the results of the survey and the author's own teaching experience, this paper discusses the above problems. 


\section{Research Objects and Method}

There are many methods to evaluate the teaching effect, such as expert evaluation, peer evaluation, etc. Students as the main participants in teaching activities and teaching activities of the audience, the teaching effect has a high voice. At the same time, the traditional teaching method Chinese emphasizes individualized, even the same material, the same courses for different students, teaching methods should be different. In this regard, the students' needs is very important. In the process of teaching in a timely manner to collect student feedback is conducive to the timely adjustment of teaching direction, and for the subsequent teaching experience.

Combining these two aspects, the author carries on the questionnaire survey to the 2013 grade students majoring in economics. Survey of 260 questionnaires issued and recovery of valid questionnaires of 257. Although the survey sample is limited, but the students are able to fill in according to the actual situation, so the collected data has a certain degree of typicality, can reflect the views and requirements of students from a certain side.

In this paper, the questionnaire is designed according to the contents of the questionnaire survey of the bilingual teaching in the undergraduate course of the Ministry of education of china. The 20 questions involved in the questionnaire are closed questions, of which there are 15 single choice questions and a multiple choice questions of 5. Involves the students to carry out all aspects of bilingual teaching, including the objectives of bilingual teaching, bilingual teaching, bilingual teaching quality course teaching mode of bilingual teaching, bilingual teaching, the suitable proportion of the evaluation methods, the factors influencing the bilingual teaching effect of bilingual teaching, suggestions and views.

\section{Results and Analysis}

Based on the statistical analysis of the results of the investigation, we analyze the results from the aspects of effect evaluation and factor analysis.

Evaluation on the Effect of Bilingual Teaching. In the list of bilingual teaching of the course, $95.83 \%$ students presented that it could improve the level of foreign language, $91.67 \%$ of the students in the professional has been improved, and the distribution in different English level, through the four grade students compared with those by students of the four grade, the two the proportion is higher.

In view of the issue of bilingual teaching in the future, $86.3 \%$ of the students believe that bilingual teaching should be quality assurance increase. While no students believe that temporarily not implemented. Setting up bilingual teaching quality of this year, $32.6 \%$ of the students choose very satisfied, $57.5 \%$ of the students chose satisfied, while $5.3 \%$ of the students with not satisfied, $4.6 \%$ of the students gave that it is difficult to evaluate.

The Factors Influencing the Achievement of Bilingual Teaching. The goal is not only the direction of our teaching activities, but also the starting point of our teaching activities. At the same time, the goal is also about the curriculum setting, teaching content and methods of choice, but also determines the implementation of teaching and evaluation indicators. From the survey situation, 91.67\% of the students think that to improve the professional knowledge, $95.83 \%$ of the students think that bilingual teaching improves the English level, at the same time, 59.38\% of the students think that the bilingual teaching of the broad field of vision. From the questionnaire data, bilingual teaching is more challenging than the traditional language education work, it should be based on ensuring the students traditional teaching task, and enhance students' English ability, and expand its international vision.

Since bilingual teaching can promote students in many aspects, what are the main factors that affect the quality and effectiveness of bilingual teaching in terms of the effect of practice? Bilingual teaching is still in the initial stage for most of the universities in china. Bilingual teaching is a challenge for both teachers and students. On the whole, the quality of teachers, the attitude of students, the use of teaching materials, the adaptation of teaching environment and conditions, as well as the teaching methods and means are the factors that influence the teaching effect. So what are the more important factors in these factors? From the survey, we found that: $72.3 \%$ of the students think that the appropriate teaching 
methods and means is very important; $59.7 \%$ of the students think that the appropriate guidance of teachers directly affect the effectiveness of bilingual teaching. These two aspects should also be the focus of our next phase of work.

Suggestions for Improving Bilingual Teaching. In addition to the general and objective questions mentioned above, we also collected some views on the teaching details in the questionnaire. $73.6 \%$ of the students believe that the original textbook should be used, and of which $58.9 \%$ of the students tend to choose the material with Chinese notes. It can be seen that for the first grade students, language is still a big difficulty in bilingual teaching. Second, the proportion of Chinese and English teaching. From the survey results, $72 \%$ of the students think that the $50-70 \%$ English ratio is more appropriate, visible despite the English level of students are different, but they are still on the bilingual teaching have a common expectations, that is not made a neglected bilingual teaching language factors professional basic course, cannot put bilingual teaching into professional English class. Third, assessment methods. In the survey, we found that $82.3 \%$ of the students gave that examinations should be used English proposition, of which $46.7 \%$ of the students choose English answer.

\section{Conclusions}

Compared with the traditional teaching of economics, the theory and practice of bilingual teaching of positioning is relatively high, it will be a long-term task of reform, not a short duration of time can be realized. Bilingual teaching of undergraduate professional courses in economics is an important innovation, feedback from the questionnaire, the students practice on Bilingual Teaching Reform in principle of economics is yes.

Clear Orientation and Goals. Let us return to the definition of bilingual teaching, bilingual teaching is generally refers to the use of Chinese, in addition to use a foreign language as the language classroom of non language teaching, so that students in the mastery of professional knowledge, improve the level of foreign language. In this sense, bilingual teaching is not only to use English teaching, but also to learn English through professional knowledge, through professional learning to improve the English language, thus shaping the bilingual thinking. Some scholars believe that the bilingual teaching and the traditional English language teaching and language teaching Chinese compared in many aspects are different, so the goals embodied in three levels: language knowledge, thinking, target. Therefore, the goal of bilingual education in economics is not English, but to broaden the horizons of students, improve their professional quality, and then develop their own culture. In view of this, the author thinks that the economics of bilingual teaching has three levels: the primary goal is to teach the same professional knowledge and Chinese target; intermediate goal is to improve the English level and the ability to grasp the common economics "in the international environment; the high level language" which aims to train bilingual thinking ability, cultivating students' international vision and the awareness of intercultural communication.

Choose Appropriate Teaching Materials. Teaching material is an important part of teaching activities. For the students entering the University, many of them can not adapt to the teaching method of pure lectures without the teaching materials, so the selection of appropriate teaching materials is an important part of the bilingual teaching of the principles of economics. At the same time, in accordance with the provisions of the Ministry of Education, bilingual education should choose the version of the textbook. As the basic course of economics, the principle of economics is not only responsible for the introductory role of economics, but also the continuation of other related courses, especially the intermediate western economics. In the choice of teaching materials, we must take into account the basic and interesting, but also to ensure a certain degree of difficulty, in order to establish adequate basic training in economics.

In general, when choosing teaching material, should consider the following principles: first, interesting. The domestic textbook relatively speaking, foreign textbook is good at describing the theory of economics in layman's language. Teaching materials are also more likely to use cases and live stories to help students build the framework of economics, and effectively cultivate students' interest in learning. Of course, such a fun need to have a degree. Too much CASESTUDY will make the teaching is bloated, 
but also easy to make students in the learning process of losing the sense of direction. Second, Standard. The content of economics is very complicated, and it is not possible for any textbook to incorporate all the contents. This problem in the microeconomics principle part is not significant, but in the course of the principle of economics stage, due to differences between the views of Keynes principle and classical economics, economics, and the book of the author itself is often advocate for a school. This time it is important to choose. Three is the theory of rigor. As the entry materials, many in order to take care of the public reading taste, expression of sacrifice economics mathematics, some core concepts, such as optimization and equilibrium of micro economics, economics principle of IS-LM and AD-AS processing simplified. Such a choice is not a problem for non - majors, but it is not easy for the students of economics. Four is the accessibility of the supplementary information. Some of the large house launched by the circulation of materials, its advantages are often not only lies in the textbook, but also in its revised the teaching materials, including teachers, student handbook and so on, one of the factors to be considered in this is the selection of teaching materials.

Reasonable Choice of Teaching Content, Reasonable Arrangements for Teaching Progress. The original textbooks are usually long, more chapters. It is not possible for all of the school year plans to be completed. At the same time, in the teaching process, because of professional courses, and is bilingual, for the key and difficult section, often need to slow down the progress of research on curriculum reform, language, with the necessary Chinese detail explanation, make sure that the students can understand the relevant knowledge. This requires that in order to give appropriate streamlining and trade-offs, to ensure that the focus at the same time, but also to maintain the rhythm of the content given. Another example of the principles of economics in the analysis of monetary issues, the general introduction of a country's financial system. For such content, understanding is not difficult, the theory is not high, but a certain amount of space, it will be assigned to the students to learn it.

Students should Have a Good Understanding of English Application Ability. At the time of the creation of Principle of Economics, students are usually in grade one or two, the English standards are often just completed complete grammar learning, vocabulary is about 4000 , and the basic vocabulary can not be applied flexibly. Second, the economics curriculum in the settings, from the primary to the intermediate, and then to the advanced, the more upward, the lower the vocabulary requirements. The primary principle, because it involves a large number of stories, case studies and descriptive language, but is the most abundant vocabulary stage. One side is a higher language requirements, on the other side is the lack of students' language foundation. This requires teachers to have a clear understanding of the students' language ability and the difficulty of the course, and use appropriate teaching methods in the teaching process. Bilingual teaching model has been mentioned in the beginning, there are three: one is the transitional type, namely teaching of the mother tongue, English is to maintain proper penetration two types, namely teaching in Chinese and English together, used interchangeably. However, if the transition teaching is used too much, it may not be able to achieve the purpose of bilingual teaching itself. For foreign language students is relatively weak, with a professional course, we tend to have flexible grasp of these three kinds of different teaching modes in the teaching process step by step.

Western Theory, Local Case. In the course of teaching, a large number of cases and theories come from the history of economic history and economic thought, rather than on theory and theory. While the use of foreign textbooks, because the content of teaching materials is not for the purpose of China such as tailor-made, Mankiw materials are discussed in the financial system, the Fed as the blueprint of all sorts of policy about fiscal and monetary policy, Greenspan and Bekenan's tendency to enumerate. This requires teachers in the teaching of China, economic history and economic reality, have enough local cases around the principle. Students can grasp the relevant theories, they can form a preliminary concept of local economic fact. In fact, combined with the western theories and the Chinese case can be through the principle of the economics teaching, from the reflection of the demand and supply part of the China practiced a planned economy to discuss the problems in the Chinese high price elasticity. This combination gives economics teachers and students more leeway in neutral foreign textbooks and teaching. 


\section{References}

[1] YU Liming, Bilingual Teaching and College English Teaching Reform, Journal of Higher Education, 3(2005)32-34.

[2] Huang Chongling, Analysis of the core concepts of bilingual teaching, Foreign Language, 1(2008)87-93.

[3] Richards, Longman Dictionary of Applied Linguistics, Longman Publishing Group, 1985.

[4] Wu Jingjie, Impact of bilingual teaching implementation of the factors and countermeasures. Chinese University of teaching, 5(2008)110-120.

[5] Xu Hongchen, Effects of English Learning Motivation and Self-identity on Bilingual Teaching Attitudes of College Students, Journal of Beijing Second International Studies University, 18(2008)44-52.

[6] He Zhihao, Bilingual teaching of economic specialties in colleges and universities, Heilongjiang Education: Higher Education Research and Evaluation, 7(2009) 21-29.

[7] Liu Fagong, International Trade Practice English, Hangzhou: Zhejiang University Press, 2002.

[8] Liu Yinan, Bilingual teaching to improve the results - Microeconomics teaching as an example, Journal of Sichuan College of Education. 7(2009)78-83.

[9] Li Shuhua, Microeconomics bilingual teaching practice and thinking, Changzhou Institute of Technology (Social Science Edition), 7 (2008)88-94.

[10]Xiong Wei, International Trade Practice English. Wuhan: Wuhan University Press, 2001. 